\title{
Providing Power Supply to Other Use Cases Integrated in the System of Public Lighting
}

Preliminary Communication

\author{
Jurica Perko \\ Regional Energy Agency North \\ M. Krleže 81, Koprivnica, Croatia \\ jurica.perko@rea-sjever.hr
}

\section{Danijel Topić}

J. J. Strossmayer University of Osijek

Faculty of Electrical Engineering, Computer Science and Information Technology Osijek

Kneza Trpimira 2B, Osijek, Croatia

dtopic@etfos.hr

\section{Damir Šljivac}

J. J. Strossmayer University of Osijek

Faculty of Electrical Engineering, Computer Science and Information Technology Osijek

Kneza Trpimira 2B, Osijek, Croatia

dsljivac@etfos.hr

\begin{abstract}
Smart city is an attractive way of making the city more livable through intelligent solutions that are enabled by information and communication technology. Regarding the lighting system, it achieves the perfect balance between beautiful city ambience and preserving the darkness that makes cities more livable. As a smart city component, a public lighting system offers much more than light itself. Integration of other use cases has given a new dimension to the public lighting system in visual and functional terms. All those features that could be integrated into the public lighting infrastructure require additional power supply. This paper deals with possibilities of providing electricity to other power use cases integrated into the system of public lighting. Simulation results in DIALux showed that it is possible to save energy by a transition to LED lighting technology and establishment of a smart lighting management system using a dynamic operational profile proposed in the paper. By means of that, it is possible to reduce energy consumption in the public lighting system by at least $50 \%$ up to $80 \%$, which could be enough for power use cases integrated into the public lighting infrastructure.
\end{abstract}

Keywords - energy efficiency, energy performance indicator, LED technology, public lighting, smart city

\section{INTRODUCTION}

A public lighting system is a very important component of the smart city concept. Taking into account the fact that its infrastructure is unused during the day and that the system of public lighting is well developed in urban areas, it is possible to exploit it for multiple purposes. Therefore, local authorities must not observe the public lighting infrastructure only as an illumination tool for roads. There are many more opportunities to observe it as a shared infrastructure taking into account other possibilities that result in cost reduction and revenue assurance. Exploitation of public lighting infrastructural possibilities as well as possibilities and solutions of the connected public lighting management system has been researched in [1, 2, 3, 4 and 5].
To be able to use features integrated into the public lighting infrastructure it is necessary to keep lampposts powered 24 hours a day. In addition, it is necessary to interconnect all lampposts and connect them to the central management system. There are numerous solutions to avoid additional expenses to power integrated features in the public lighting infrastructure. First of all, it is a transition to LED technology due to the fact that LED requires less energy by itself. Another very important fact is that LED lighting is more easily manageable in comparison with other types of lighting sources which cause additional reduction in electricity consumption.

Smart public lighting needs to be operated remotely because each lamp should be switched on or off and dimmed automatically at any time. The basic concept 
of a manageable public lighting system with exploited infrastructure is shown in Fig. 1.
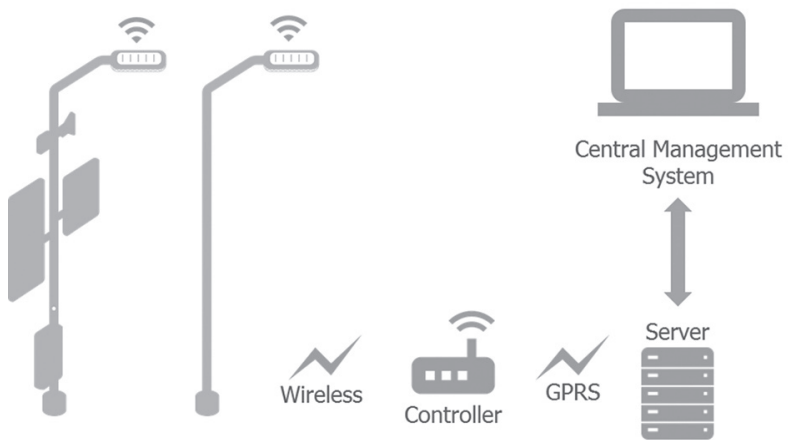

Fig. 1. Connected public lighting network [2]

In what follows, an overview of the use cases that can be integrated into the public lighting infrastructure is given. Emphasis is placed on lighting control due to its significant impact on energy performance indicators which are key quantities for system efficiency rating. The possibility of providing electricity to power use cases integrated into the public lighting system without increasing costs was investigated. Simulation results showed whether it is possible to save energy by a transition to LED lighting technology and establishment of a smart lighting management system using a dynamic operational profile proposed below.

Paper [2] deals with the possibility of exploiting the public lighting infrastructure for multiple purposes. All of use cases that can be integrated into the public lighting infrastructure need power for their operation. This paper analyzes the possibility of providing power supply to these use cases without generation of additional costs by choosing an adequate operational profile for the lighting system.

\section{EXPLOITATION OF THE PUBLIC LIGHTING INFRASTRUCTURE}

\subsection{PUBLIC LIGHTING INFRASTRUCTURE UTILIZATION}

As a smart city component, a public lighting system offers much more than light itself. Smart city is an attractive way of making the city more livable through smart solutions that are supported by information and communication technology [3]. According to the Croatian legal framework, a public lighting system has become a communal activity. Since 1998, the Croatian electricity utility has transferred ownership of the equipment to local government. In line with the fact that public lighting can consume as much as $40 \%$ of the municipal energy budget and considering that the public lighting system is not fully utilized, local authorities must exploit it thoroughly. Therefore, there is a great potential to reduce electricity and operational costs by establishing smart public lighting. The first step is to replace the existing lamps with LED-based technology that will result in reduction of energy and operational costs. By connecting those LED lamps municipalities can additionally cut energy costs which is a result of real-time intelligent management and faster response. Smart public lighting includes many functional units such as a remote management system, sensors for traffic monitoring, a traffic counter, digital traffic signs, integrated electric vehicle charging stations, etc. A combination of all these features makes a public lighting system smarter and more exploited. At the same time, this is a good way to establish a smart lighting system and an intelligent traffic system.

There are a lot of use cases that can be integrated into the public lighting infrastructure (Fig. 2.).

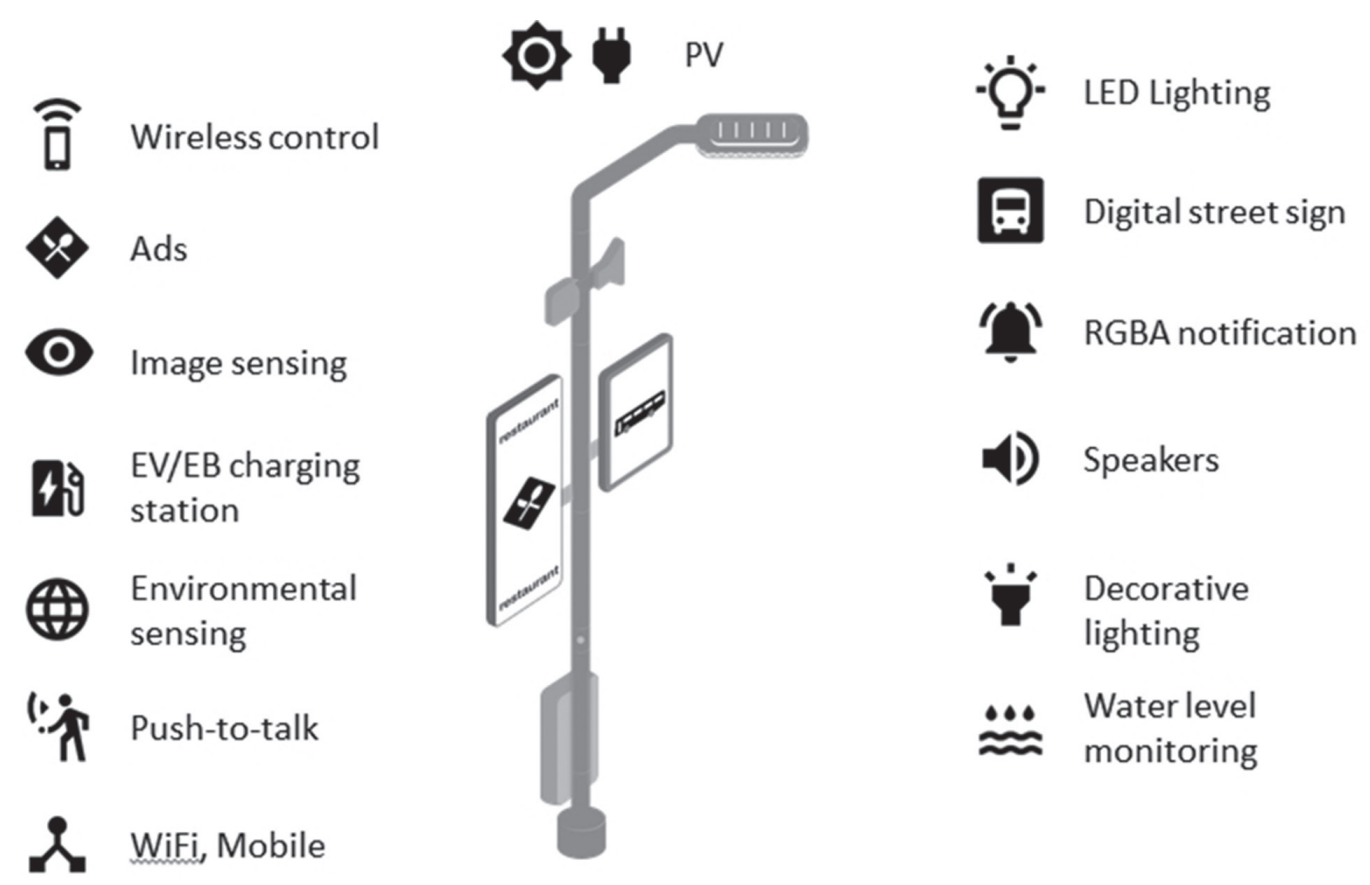

Fig. 2. Features that can be integrated into the public lighting infrastructure 


\subsection{LIGHTING CONTROL WITH PRESENCE SENSORS AND DETECTORS}

Due to well-coverage of municipalities by the public lighting infrastructure it is possible to establish an intelligent traffic system. Traffic flow could be monitored by installing presence sensors and detectors on lampposts positioned along the street [6].

Around midnight, when the traffic calms down and people retreat to their homes, there is no need for nominal illuminance on the street which is caused by nominal lamp power $\left(\mathrm{P}_{\text {car }}\right)$. Therefore, at a certain time e.g. at $11 \mathrm{pm}$, the power of the lighting system is reduced to the minimum $\left(P_{\min }\right)$, just to have enough light for the purpose of safety. When the sensor registers a pedestrian, the lighting power increases from Pmin to the power level that provides enough illuminance required for pedestrian safety $\left(\mathrm{P}_{\text {walk }}\right)$. Due to pedestrian safety $P_{\text {walk }^{\prime}}$ the range is the same in front of and behind the pedestrian.

In case a vehicle comes along the street, the sensor detects it and sends the information to a central monitoring and control system which gives an order to the lighting system to change the power level to $P_{\text {car }}$ Image sensors track the vehicle through the street and give an order to the lighting system to change the lamp power level in front of and behind the vehicle as shown in Fig. 3. The lighting power reduces to the minimum immediately behind the vehicle and increases to the nominal level as long as necessary for the purpose of ensuring safe traffic flow.

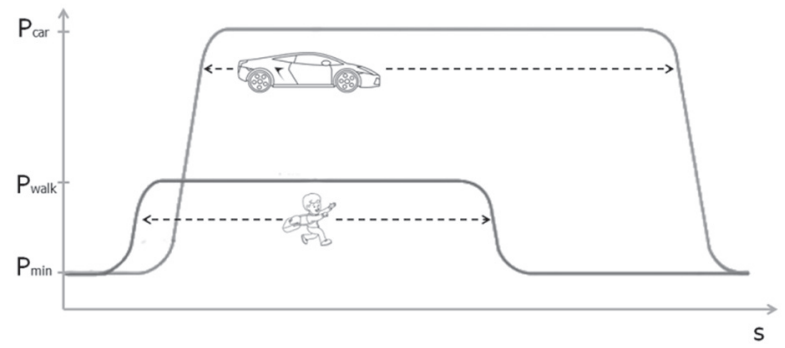

Fig. 3. Traffic flow monitoring - presence sensors and detectors

This concept is accompanied by European Standard Road lighting - Part 5: Energy performance indicators EN13201-5:2015. In combination with LED lighting technology it provides more energy reduction which could compensate energy consumed by the use cases described above.

\section{ENERGY PERFORMANCE INDICATORS FOR ROAD LIGHTING INSTALLATIONS}

Energy performance indicators may be used for comparison of energy performance of different lighting solutions for the same project of a road lighting system. They are defined by the EU Standard EN 13201-5:2015. Here we show three examples of operational profiles that illustrate a daily course of the lighting level. This section also describes energy performance indicators for road lighting installations, which includes a power density indicator (PDI) and an annual energy consumption indicator (AECI) [7, 8, 9, 10 and 11].

\subsection{PUBLIC LIGHTING OPERATIONAL PROFILES}

There are three typical operational profiles for a lighting system. These examples illustrate a daily course of the lighting level. The power level needed for the calculation of energy performance is associated with lighting levels depending on a lamp type, power and other factors [11].

The most common operational profile is a full-power operation profile which is typical for the lighting system with simple switching devices such as time switchers or photosensors. Lamps operate each day constantly at full power throughout the night, Fig. 4.

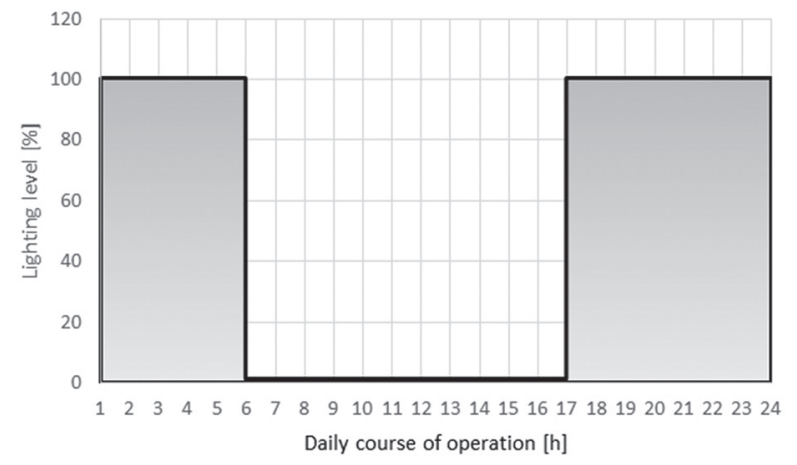

Fig. 4. Full-power operational profile

Fig. 5. shows a profile that consists of two or more time periods during the day with lamps operating at different power associated with different lighting levels provided. This profile is known as multi-power operation (e.g. a bi-power operational profile).

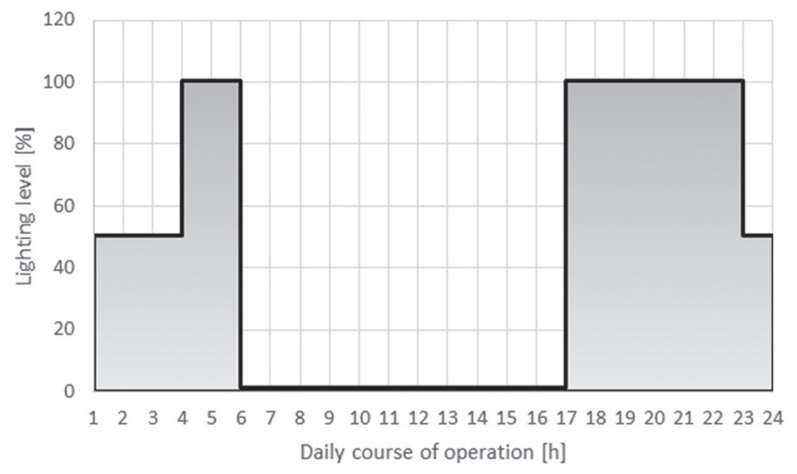

Fig. 5. Bi-power operational profile

Operational profile with presence sensors and detectors results with energy savings. Example of tri-power operational profile where at least a minimum lighting level is kept throughout the night time is shown as follows, Fig. 6. Lighting level peaks are not periodically, they depend on sensing. 


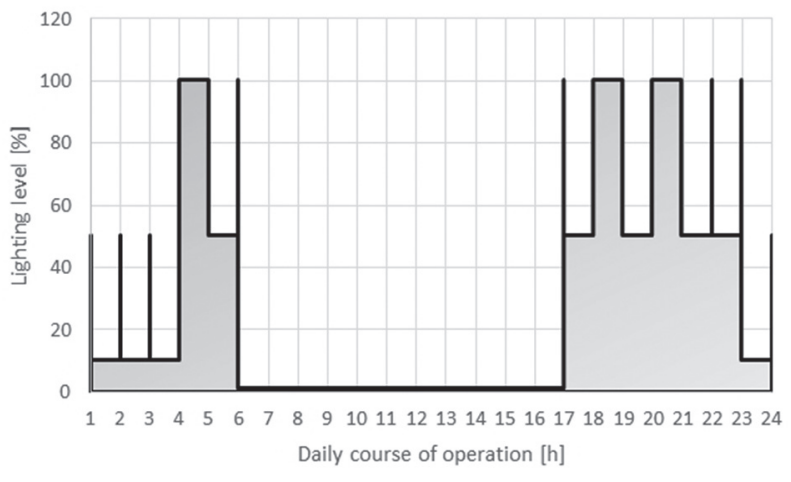

Fig. 6. Tri-power operational profile

\subsection{ENERGY PERFORMANCE INDICATORS}

The fifth part of the EU Standard EN 13201 defines how to calculate energy performance indicators for road lighting installations including the power density indicator (PDI) and the annual energy consumption indicator (AECI) [11]. Just briefly, according to [9], the PDI is a value of the system power divided by the value of the product of the surface area to be lit and the calculated maintained average illuminance value on this area. It is calculated in a given state of operation and could be represented by the following expression [11]:

$$
D_{P}=\frac{P}{\sum_{i=1}^{n}\left(\overline{E_{i}} \cdot A_{i}\right)},
$$

where:

$D_{P}$ - power density indicator;

$P$ - total system power of the lighting installation used to light the relevant areas;

$E_{i}$ - maintained average horizontal illuminance of the sub-area "i";

$A_{i}$ - size of the sub-area " $i$ " lit by the lighting installation; $n$ - number of sub-areas to be lit.

The annual energy consumption indicator in a specific year is total electricity consumed by a lighting installation day and night throughout a specific year in proportion to the total area to be illuminated by the lighting installation. The $\mathrm{AECl}$ is calculated by means of the following formula [11]:

$$
D_{E}=\frac{\sum_{j=1}^{m}\left(P_{j} \cdot t_{j}\right)}{A},
$$

where:

$D_{E}$ - annual energy consumption indicator for a road lighting installation;

$P_{j}$ - operational power associated with the $j^{\text {th }}$ period;

$t_{i}$ - duration of the $j^{\text {th }}$ period of the operation profile when the power $P_{j}$ is consumed;

$A$ - size of the area lit by the same lighting arrangement; $m$ - number of periods with different operational power.
Values of energy performance indicators depend on many parameters such as the actual lighting class, road and sidewalk width, type of the light source, etc.

In case of the $\mathrm{AECl}$, the switching and control profile strongly influences value change. Those values apply to the full-power operational profile with 4,000 annual operating hours. To take into consideration different operational profiles it is necessary to consider annual operation periods of individual lighting levels with the associated power and the presence detection probability in order to define the single lighting operation coefficient $c_{o p}$. This coefficient could be multiplied by the $A E C I$ value for full-power operation to obtain the AECI value for the actual operational profile [12].

For AECl calculation, it is necessary to assume the annual probability parameter for each of the lighting levels [11].

$C_{\text {op }}$ coefficient is expressed in the table below in percentage under the following assumptions defined in [11]:

- Full power $-4,000 \mathrm{~h}$ of operation at full power $P$.

- Bi-power $-2,175 \mathrm{~h}$ at full power $P$ and $1,825 \mathrm{~h}$ at reduced power $0.7 \cdot P$ with lighting level reduced to $50 \%$.

- Tri-power $-2,175 \mathrm{~h}$ of bi-level lighting control between $100 \%$ and $60 \%$ of the system power with detection probability of $80 \%$ and $1,825 \mathrm{~h}$ of reduced bi-level lighting control between $20 \%$ and $60 \%$ of system power with detection probability of $20 \%$.

Table 1. Typical values of the lighting operation coefficient

\begin{tabular}{|cc|}
\hline Operational profile & cop [\%] \\
\hline Flat full power & 100.0 \\
\hline Bi-power & 86.3 \\
\hline Tri-power & 62.8 \\
\hline
\end{tabular}

\section{METHOD AND SIMULATIONS}

The main objective of these simulations is to investigate a possibility of providing electricity to power use cases integrated in the public lighting system without increasing costs. One of the most popular and most harmless solutions is a smart lighting management system. By installing presence sensors and detectors, it is possible to manage the lighting system as described previously. Two most common technologies are discussed in this section (high pressure sodium and LED technology), which are compared in terms of energy performance indicators by lighting classes for a predefined road profile.

Typical values of energy performance indicators are given in the EU Standard EN 13201-5 for different road profiles by lighting classes but they are not adequate for Croatian roads due to e.g. unreasonable width of 
the carriageway or similar parameters that has a great impact on the PDI and the AECI. The PDI and AECI values depend on many factors such as lighting class, road profile arrangement, width of the carriageway, type of the light source, optics and position of the lamp, etc. Because of that, it is inevitable to simulate road lighting with appropriate parameters. The $\mathrm{AECl}$ also depends on the switching and control profile.

It is important to note that a lower PDI and AECI value implies better energy performance. Another very important fact is that values should not be used as benchmarks, but they can give you a sense of how some solution is more or less energy efficient [11].

A generic road profile simulated in professional lighting design software (DIALux) is shown in Fig. 7. Lighting poles are installed beside the road, 0.5 meters from the edge. One luminaire is installed per pole. The arrangement of the lighting system is single-sided. Lamp types used in simulation comprise tubular high pressure sodium (HPS) lamps and LEDs of different wattage.

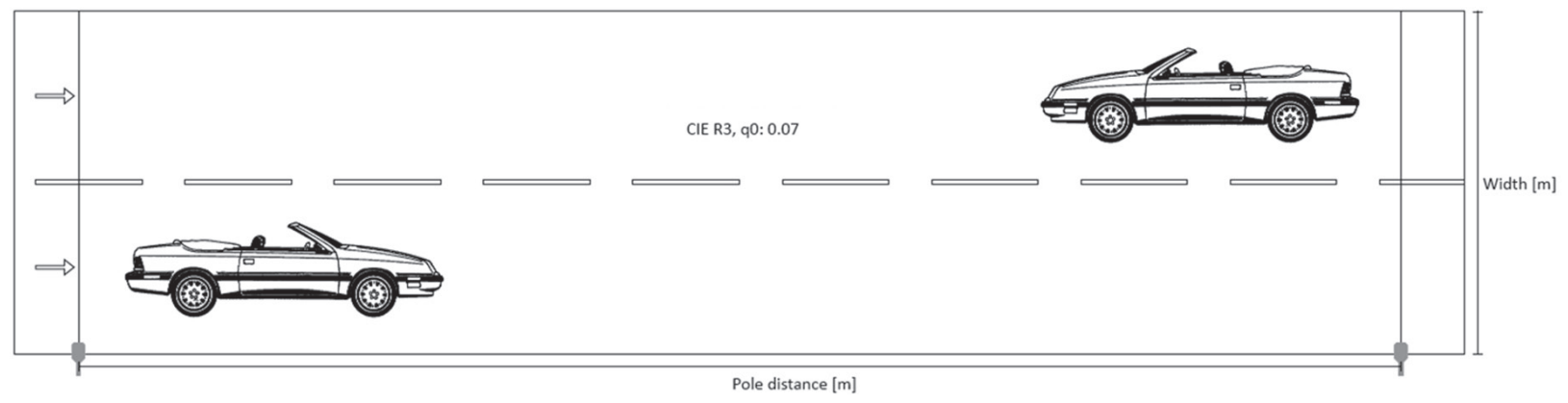

Fig. 7. Two-lane road for motorized traffic

Simulations are conducted by considering the following assumptions:

- $\quad$ width of the carriageway range from $3.5 \mathrm{~m}$ to $8 \mathrm{~m}$ depending on lighting class;

- maintenance factor is set to 0.67 for all types of lamps and luminaires according to CIE: 97:2015, which depends on ageing of the lamp, lamp failures, dirt on the luminaire and dirt on light reflecting surfaces;

- roadway characteristic is defined according to the R-Table, where road reflection properties CIE R3 are considered [13];

- mounting height is set to $6.5 \mathrm{~m}$ for the lower three classes and to $9.5 \mathrm{~m}$ for the upper three classes;

- $\quad$ spacing of lighting poles is optimized and sought between $25 \mathrm{~m}$ to $40 \mathrm{~m}$ following the rules recommending that the minimum distance between the columns is greater by 3.5 height of the lighting poles, where applicable;

- boom length range from $0.5 \mathrm{~m}$ to $1 \mathrm{~m}$;

- luminaires are not tilted;

- operational profile is set to full power with annual operating time of 4,000 hours;

- LED lighting technology has correlated color temperature of $3,000 \mathrm{~K}$;

- $\quad$ all requirements for lighting classes are met.

Previously considered assumptions were selected as most common values used in public lighting design according to $[7,8,9,10$ and 11$]$.

The observed area, which is a reference area for obtaining results, is the area between two poles as shown in Fig. 8.

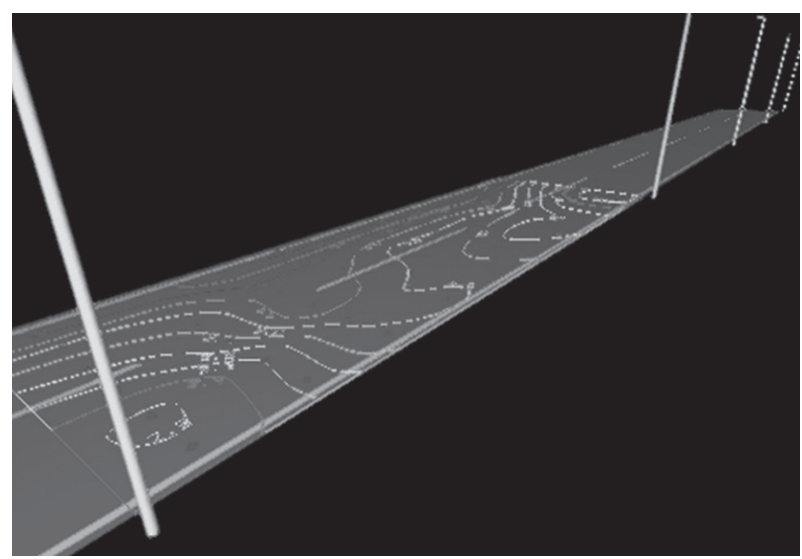

Fig. 8. Observed reference area

There are also some other approaches to maximizing energy efficiency in the public lighting system which are described in [14 and 15]. These approaches are based on a simple method for rough but sustainable calculations which provide a general procedure for designing public lighting. The main difference between these approaches described above and the approach used in this paper lies in the fact that these approaches are based on lighting design and calculations but our approach is based on management and operation solutions.

\section{RESULTS AND INTERPRETATION}

Results of six simulations for the HPS lamp (each for one lighting class) and six simulations for the LED lamp are interpreted in this section. The results of our study which refers to the PDI and the $\mathrm{AECl}$ are listed in Table 2 and Table 3. The data for each lighting class includes the width of the carriageway and the mounting height. The last two columns in the table show the PDI or the $\mathrm{AECI}$ for both lighting technologies. 
By comparing the PDI for HPS and LED technology it can be noticed that LED has a much better PDI value than HPS. The reason lies in the fact that LED lighting technology has much better luminous efficacy which includes good optics.

The results are quite different from the typical values of the power density indicator proposed in [11], especially for lower lighting classes. This difference is primarily caused by a disproportionate relationship of lighting classes and the width of the carriageway.

Table 2. Values of the power density indicator for the observed road profile

\begin{tabular}{|c|c|c|c|c|}
\hline \multirow[t]{2}{*}{$\begin{array}{l}\text { Lighting } \\
\text { class }\end{array}$} & \multirow{2}{*}{$\begin{array}{c}\text { Width of } \\
\text { carriageway } \\
{[\mathrm{m}]}\end{array}$} & \multirow[t]{2}{*}{$\begin{array}{l}\text { Mounting } \\
\text { height [m] }\end{array}$} & \multicolumn{2}{|c|}{ Lamp type } \\
\hline & & & $\begin{array}{c}\text { HPS [W/ } \\
\mathrm{Ix} \cdot \mathrm{m} 2]\end{array}$ & $\begin{array}{c}\text { LED [W/ } \\
\text { Ix.m2] }\end{array}$ \\
\hline M1 & 8.0 & 9.5 & 0.037 & 0.026 \\
\hline M2 & 7.0 & 9.5 & 0.042 & 0.028 \\
\hline M3 & 6.0 & 9.5 & 0.043 & 0.033 \\
\hline M4 & 5.5 & 6.5 & 0.053 & 0.035 \\
\hline M5 & 4.5 & 6.5 & 0.075 & 0.033 \\
\hline M6 & 3.5 & 6.5 & 0.101 & 0.037 \\
\hline
\end{tabular}

The difference between HPS and LED values is visually shown in Fig. 9.

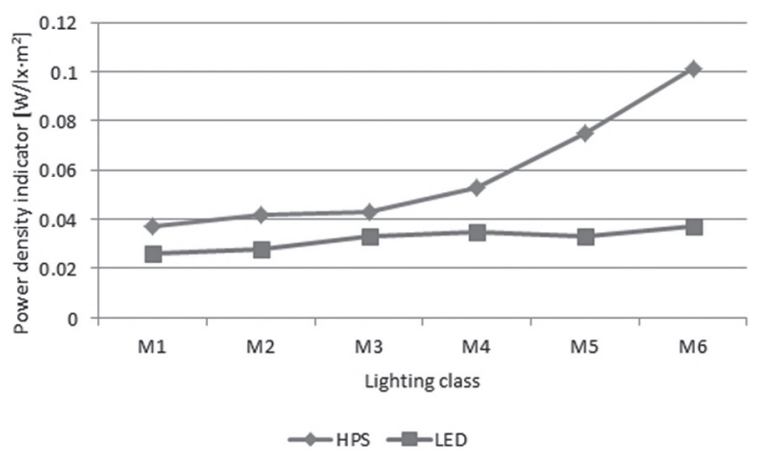

Fig. 9. Difference between PDI value for HPS and LED

The situation is similar in terms of the $A E C l$. The results show that LED has lower AECI values than HPS. It is important to note that the AECl considers the annual accumulated energy use of road lighting that may vary during the year due to seasonal variations of daylight/night time hours, changing weather conditions, changing traffic density and changing functionality of the street. Therefore, these are informative values that could provide initial information.

The difference between HPS and LED annual energy consumption indicator values is visually shown in Fig. 10 .

As previously mentioned, the $\mathrm{AECl}$ depends on public lighting operational profiles which are defined above. LED annual energy consumption indicator values for different operational profiles are compared and presented in Table 4.
Table 3. Values of the annual energy consumption indicator for the observed road profile

\begin{tabular}{|c|c|c|c|c|}
\hline \multirow{2}{*}{$\begin{array}{l}\text { Lighting } \\
\text { class }\end{array}$} & \multirow{2}{*}{$\begin{array}{l}\text { Width of } \\
\text { carriage- } \\
\text { way [m] }\end{array}$} & \multirow{2}{*}{$\begin{array}{l}\text { Mounting } \\
\text { height } \\
{[\mathrm{m}]}\end{array}$} & \multicolumn{2}{|c|}{ Lamp type } \\
\hline & & & $\begin{array}{c}\text { HPS [kWh/ } \\
\text { m2] }\end{array}$ & $\begin{array}{c}\text { LED [kWh/ } \\
\text { m2] }\end{array}$ \\
\hline M1 & 8.0 & 9.5 & 5.40 & 3.65 \\
\hline M2 & 7.0 & 9.5 & 4.54 & 3.49 \\
\hline M3 & 6.0 & 9.5 & 3.04 & 2.43 \\
\hline M4 & 5.5 & 6.5 & 3.13 & 1.71 \\
\hline M5 & 4.5 & 6.5 & 2.70 & 1.13 \\
\hline M6 & 3.5 & 6.5 & 2.74 & 0.74 \\
\hline
\end{tabular}

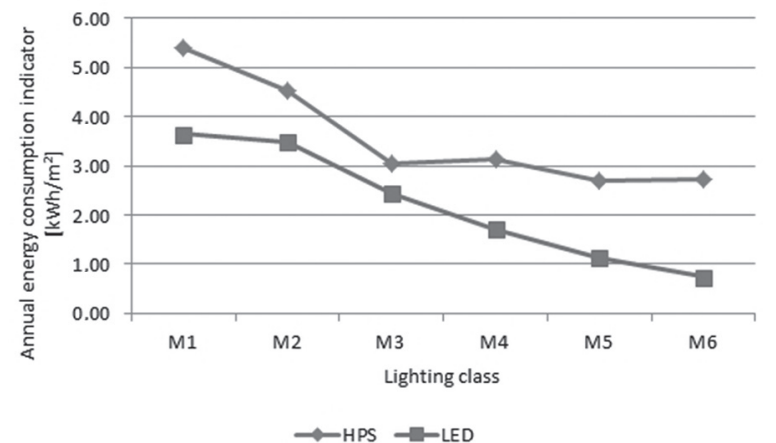

Fig. 10. Difference between $A E C I$ value for HPS and LED

Table 4. LED annual energy consumption indicator values for different operational profiles

\begin{tabular}{cccc} 
Lighting class & $\begin{array}{c}\text { Flat full pow- } \\
\text { er [kWh/m2] }\end{array}$ & $\begin{array}{c}\text { Bi-power } \\
{[\mathrm{kWh} / \mathrm{m} 2]}\end{array}$ & $\begin{array}{c}\text { Tri-power } \\
{[\mathrm{kWh} / \mathrm{m} 2]}\end{array}$ \\
\hline M1 & 3.65 & 3.15 & 2.29 \\
\hline M2 & 3.49 & 3.01 & 2.19 \\
\hline M3 & 2.43 & 2.10 & 1.53 \\
\hline M4 & 1,71 & 1.48 & 1.07 \\
M5 & 1.13 & 0.98 & 0.71 \\
M6 & 0.74 & 0.64 & 0.46 \\
\hline
\end{tabular}

Fig. 11. shows a comparison of $\mathrm{AECl}$ values for three operational profiles. It is evident, as is logical, that the profile with less working hours has favorable $\mathrm{AECl}$ values.

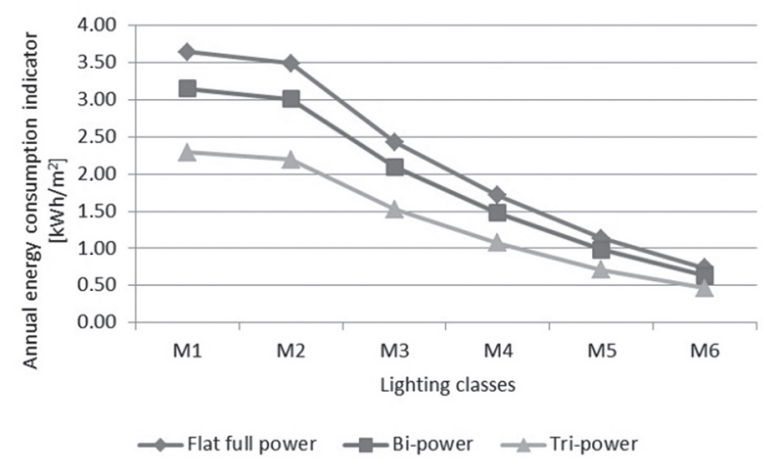

Fig. 11. Comparison of $A E C I$ for three operational profiles 
In what follows, the $\mathrm{AECl}$ is interpreted as the energy saving indicator by comparing HPS and LED lighting technology including the tri-power operational profile as the most favorable one. Table 5 gives energy savings in percentage due to a transition to LED technology and the application of the third operational profile in relation to the most commonly used lighting technology, i.e. HPS.

Table 5. AECl as energy saving indicator by implementing LEDs using the tri-power operational profile

\begin{tabular}{cccc} 
Lighting class & $\begin{array}{c}\text { HPS [kWh/ } \\
\mathrm{m} 2]\end{array}$ & $\begin{array}{c}\text { LED [kWh/ } \\
\mathrm{m} 2]\end{array}$ & Savings [\%] \\
\hline M1 & 5.40 & 2.29 & 57.61 \\
\hline M2 & 4.54 & 2.19 & 51.70 \\
M3 & 3.04 & 1.53 & 49.68 \\
\hline M4 & 3.13 & 1.07 & 65.70 \\
\hline M5 & 2.70 & 0.71 & 73.63 \\
\hline M6 & 2.74 & 0.46 & 83.08 \\
\hline
\end{tabular}

According to simulations, by a transition to LEDs, implementation of the public lighting smart management system and by installing presence sensors and detectors municipalities can significantly reduce energy consumption by at least $50 \%$ (Fig. 12).

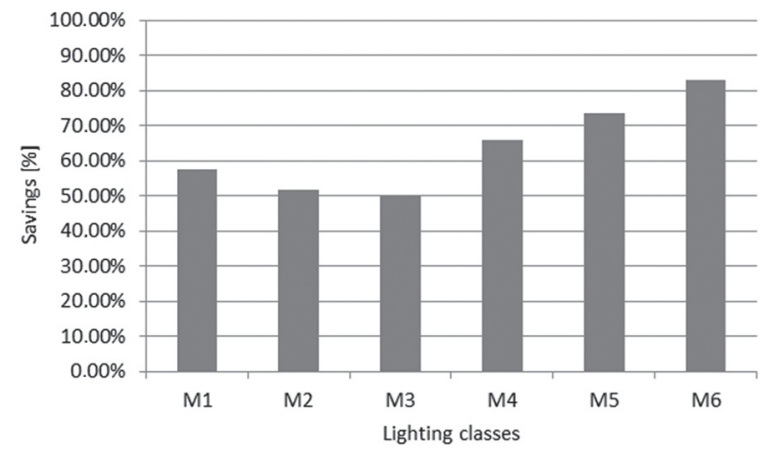

Fig. 12. Energy savings by implementation of LEDs using the tri-power operational profile

\section{CONCLUSION}

A public lighting system is a great opportunity for municipalities to improve the quality of life in their surroundings and to make everyday life safer, smarter and more efficient. Integration of other use cases into the public lighting infrastructure requires additional energy. This study shows that there is a solution to ensure additional energy by a transition to LED technology and establishment of the smart lighting management system using the tri-power operational profile. Simulation results showed that the public lighting infrastructure can ensure additional energy by avoiding extra costs. By implementing the aforementioned measures, it is possible to reduce energy consumption in the public lighting system by at least $50 \%$ up to $80 \%$, which could be enough for power use cases integrated into the public lighting infrastructure.
Results of six simulations for the HPS lamp and six simulations for the LED lamp showed that there is a greater difference between PDI values for lower road classes, M5 and M6. In all cases, PDI and AECI indicators have lower values for LEDs, which means that LED lamps are more efficient. Due to LED's full controllability it is possible to change operational modes in order to additionally decrease the $\mathrm{AECl}$ showed in Table 4 and Fig. 11. In general, in combination with tri-power operation mode, LEDs generate most energy savings.

With the aim of making decisions easier, it is necessary to conduct cost-benefit analysis or a financial comparison to give the final assessment, but due to computational complexity, these analyses will be conducted as a follow-up to this paper.

\section{REFERENCES:}

[1] C. B. Smith, K. E. Parmenter, "Energy Management Principles", 2 2nd Ed., Elsevier Inc., 2015.

[2] J. Perko, D. Topic, D. Sljivac, "Exploitation of Public Lighting Infrastructural Possibilities", Proceedings of the $1^{\text {st }}$ International Conference on Smart Systems and Technologies, Osijek, Croatia, 12-14 October 2016, pp. 55-59.

[3] E. R. Sanseverino, G. Scaccianoce, V. Vaccaro, G. Zizzo, S. Pennisi, "Smart city and public lighting", Proceedings of the 2015 IEEE International Conference on Environment and Electrical Engineering, Gijon, Spain, 10-13 June 2015, pp. 665-670.

[4] H. Pires, A. M. Carreiro, G. Pereira, R. Carreira, J. P. Trovao, J. Landeck, "IP@Smart - Energy Management System Applied to Eco-Efficient Public Lighting Networks", Proceedings of the 2014 IEEE Vehicle Power and Propulsion Conference, Coimbra, Portugal, 27-30 October 2014, pp. 1-6.

[5] A. Pena-Garcia, M. C. Aguilar-Luzon, "Impact of public lighting on pedestrians' perception of safety and well-being", Safety Science, Vol. 78, 2015, pp. 142-148.

[6] S. Gul, Y. Heekwon, A. Ahmad, L. Chankil, "EnergyEfficient Intelligent Street Lighting System Using Traffic-Adaptive Control", IEEE Sensors Journal, Vol. 16, No. 13, 2016, pp. 5397-5405.

[7] European Standard, Road lighting - Part 1: Guidelines on selection of lighting classes (CEN/TR 13201-1:2014), Brussels, Belgium, 2014.

[8] European Standard, Road lighting - Part 2: Performance requirements (EN 13201-2:2015), Brussels, Belgium, 2015. 
[9] European Standard, Road lighting - Part 3: Calculation of performance (EN 13201-3:2015), Brussels, Belgium, 2015.

[10] European Standard, Road lighting - Part 4: Methods of measuring lighting performance (EN 13201-4:2015), Brussels, Belgium, 2015.

[11] European Standard, Road lighting - Part 5: Energy performance indicators (EN 13201-5:2015), Brussels, Belgium, 2015.

[12] H. Glavas, D. Blazevic, M. Ivanovic, "Quality and energy efficiency of public lighting in the area of Osijek-Baranja County", Technical Gazette, Vol. 19, No. 3, 2012, pp. 549-556.
[13] AGi32, R-Tables for Roadway Lighting, http://docs. agi32.com/AGi32/Content/references/R-Tables\%20 for\%20Roadway\%20Lighting.htm (accessed: 2017)

[14] A. Pena-Garcia, D. Gomez-Lorente, A. Espin, O. Rabaza, "New rules of thumb maximizing energy efficiency in street lighting with discharge lamps:The general equations for lighting design", Engineering Optimization, Vol. 48, No.6, 2015, pp. 1080-1089.

[15] O. Rabaza, D. Gomez-Lorente, F. Perez-Ocon, A. Pena-Garcia, "A simple and accurate model for the design of public lighting with energy efficiency functions based on regression analysis", Energy, Vol. 107, 2016, pp. 831-842. 